\title{
In the Balance: Report of a Research Study Exploring Information for Weight Management
}

\author{
Audrey Marshall, Flis Henwood, Leslie \\ Carlin, Elizabeth S. Guy, and Helen Smith
}

Audrey Marshall, Senior Lecturer, School of Computing, Mathematical and Information Sciences, University of Brighton, Brighton, UK. Email: a.m.marshall@brighton.ac.uk

Professor Flis Henwood, Professor of Social Informatics, School of Applied Social Science, University of Brighton, Brighton, UK.

Email: F.Henwood@brighton.ac.uk

Dr. Leslie Carlin, Research Fellow, Brighton and Sussex Medical School, Brighton, UK.

Email: L.Carlin@bsms.ac.uk

Dr. Elizabeth S. Guy, Senior Lecturer, School of Computing, Mathematical and Information Sciences, University of Brighton, Brighton, UK. Email: E.S.Guy@brighton.ac.uk.

Professor Helen Smith, Professor of Primary Care and Head of Division of Primary Care and Public Health, Brighton and Sussex Medical School,

Brighton, UK.

Email: h.e.smith@bsms.ac.uk

This paper is based on a presentation at the international conference ' $\mathrm{i}^{3}$ : Information: Interactions and Impact', organized by the Robert Gordon University's Department of Information Management, and held in Aberdeen, Scotland, 22-25 June 2009.

\begin{abstract}
This paper uses findings from a research study called Net.Weight to examine the concepts of interaction, information quality and Internet-based information from the perspective of people engaged in managing their weight. The Net.Weight study was a two-year project funded by the British government's Department of Health and located in the city of Brighton and Hove. It examined the potential for increased, innovative and effective uses of information and communication technologies (ICTs) to support the
\end{abstract}

self management of weight. The study had several inter-related research strands and the findings discussed in the paper emerged primarily from participatory learning workshops and evaluative interviews. The paper demonstrates that the interaction between people is an important aspect of the information process, which is often neglected in the literature. It suggests that exploring the user-user dimension might add to the understanding of information effectiveness. It also suggests that an approach to information and health literacy which includes a social as well as an individual perspective is necessary. On quality assessment, it supports findings from other studies that organisational authority is a key measure of reliability for lay users and that quality assessment tools have a limited role in the assessment process. The Net.Weight participants embraced the Internet as a medium for weight management information only when it added value to their existing information and weight management practices and when it could be integrated into their everyday lives.

\section{Introduction}

This paper uses findings from a research study called Net.Weight to examine certain aspects of information behaviour. In particular, it explores the concepts of interaction and information quality from the perspective of people engaged in managing their weight. It also reports on the usefulness of the Internet as an information tool for weight management.

\section{Context and literature}

In the UK, the importance of information in a health policy context can be traced back to the late 1990s when the Department of Health published Information for Health (Department of Health 1998), followed by Building the Information Core (Department of Health 2001). These were key policy documents, setting out the ways in which information and ICTs would help transform the NHS and were a central 
part of the agenda to modernise the health service. The White Paper, Better Information, Better Choices, Better Health, puts information at the core of healthcare (Department of Health 2004), stating that "high quality information empowers people" and enables them to make information decisions. It also links information explicitly with self care, stating that improving information can "encourage greater selfcare", thus "reducing inappropriate pressures on areas of the health care system". The Department of Health commissioned MORI to conduct a survey of public attitudes to self care, which found that information and knowledge were indeed likely to be key factors in enabling better self care (Department of Health 2005). The Picker Institute conducted a similar survey, measuring self engagement in health care (Ellins \& Coulter 2005) and the report also stresses the role of information in enabling individuals to be actively involved in their health and healthcare.

A series of online information initiatives were developed in line with this UK policy direction, including NHS Direct Online (National Health Service 1999) and more recently NHS Choices (National Health Service 2008) and Information Prescriptions (National Health Service 2009) and indeed, the growth of consumer health information initiatives has been partly driven by the rapid expansion of the Internet (Cline \& Haynes 2001). Alongside the growth of the Internet as a medium has been a growing and well documented concern over the quality of health information on the Internet (Eysenbach et al. 2002).

Assessing or evaluating the quality of information is one of the key competencies encompassed in most definitions of information and related literacies. The definition of information literacy by the U.K. Chartered Institute of Library and Information Professionals (2007) and the U.S. Medical Library Association definition of health information literacy (Medical Library Association 2005) both make this explicit, while the Institute of Medicine (2004), in its definition of health literacy, uses 'process and understand' of health information. Similarly, Norman and Skinner (2006) include the 'ability to appraise' health information in their definition of e-health literacy. Thus it is important to devise ways of helping people to develop evaluation skills or, as Childs puts it, of "empowering health consumers to judge the quality of Internet health information" $(2004,15)$. Childs (2004) and Wilson (2002) chart the rise in the development of quality assessment tools, which have been seen as key in this process. However, as Adams, Bont, and Berg (2006) note, there remains a gap in understanding around the contribution that such tools make in practice to people's everyday information activities, despite a recent research focus on this issue. For example, (Eysenbach \& Kohler 2002) and Childs (2004) both used focus groups to investigate how consumers appraise health information and use assessment tools. Adams, Bont, and Berg (2006) used interviews and observation to conduct a similar investigation while Marshall and Williams (2006) used 'information review groups' to examine whether and how the public make quality judgements about health information over a variety of media.

These studies articulate in practice a conceptual approach to information literacy which emphasises the context of everyday life. Johnston and Webber (2006) outline the role of information literacy as a way to support citizens in the information age, Kuhlthau (2008) discusses the use of information in the context of the workplace and daily living and McKenzie (2003) develops a model to reflect everyday life information seeking. Kuhlthau (2008) argues that people with everyday life information needs, including health-related needs, construct their information from a variety of sources over an extended period of time. She cites Bates' berry picking metaphor (Bates, cited in Kuhlthau 2008, 67) to illustrate that people move from one source to another and extract only certain items for use. McKenzie (2003) demonstrated similarly that, in everyday situations, people move fluidly from one type of information seeking behaviour to another, for example from contacting a doctor to looking something up in a book to engaging in conversation with another person in a similar situation.

Williams (2008) argues that those engaged in information literacy are "also concerned with the userinformation interaction" and with making this interaction more effective. In the context of consumer health, this interaction is seen as vital: "good health decisions depend on good information" (Medical Library Association 2005). On health literacy, the MLA states that "health literacy is a vital component of consumer health." Kars, Baker and Wilson (2008, xi) and Coulter and Ellins similarly state a relationship between the concepts of consumer health information and health literacy: "the delivery of high 
quality and appropriately targeted consumer health information is central to the delivery of health literacy" (Coulter \& Ellins 2006, 27). They argue that public debate and policy in the UK have been more focused on the provision of health information than on health literacy. Nutbeam (2008) traces the development of the health literacy concept, arising from public health and health promotion disciplines, which focuses less on a set of functional capabilities and more on a set of skills which enable people to participate in their own health and well-being:

Health literacy represents the cognitive and social skills which determine the motivation and ability of individuals to gain access to, understand and use information in ways which promote and maintain good health. (World Health Organization 1998)

This definition is notable for its incorporation of social, as well as cognitive, skills and for the inclusion of other attributes such as motivation, reflecting Kuhlthau's (2008) "affective" realm of experience which, she argues, is part of a holistic view of information seeking.

\section{The Net.Weight study}

The Net.Weight study, officially called Supporting the self management of obesity: the role of information and communication technologies (Henwood et al. 2009) was a two-year project funded by the Department of Health. It examined the potential for increased, innovative and effective uses of information and communication technologies (ICTs) to support the self management of weight. The study was located in the city of Brighton and Hove and conducted by an inter-disciplinary team from the University of Brighton and Brighton and Sussex Medical School (which is a partnership between the Universities of Brighton and Sussex with the NHS).

The study had several inter-related research strands, as illustrated in Figure 1. The findings discussed in this paper emerged primarily from the participatory learning workshops and evaluation strands, with additional data from the user mapping strand. The three methods are outlined here.

The user mapping strand of the study used focus groups and a questionnaire based survey to establish benchmark data about people's behaviour with regard to weight management. It examined respondents' awareness and use of information sources for
Figure 1: Flow diagram showing the inter-related research strands of the Net.Weight study

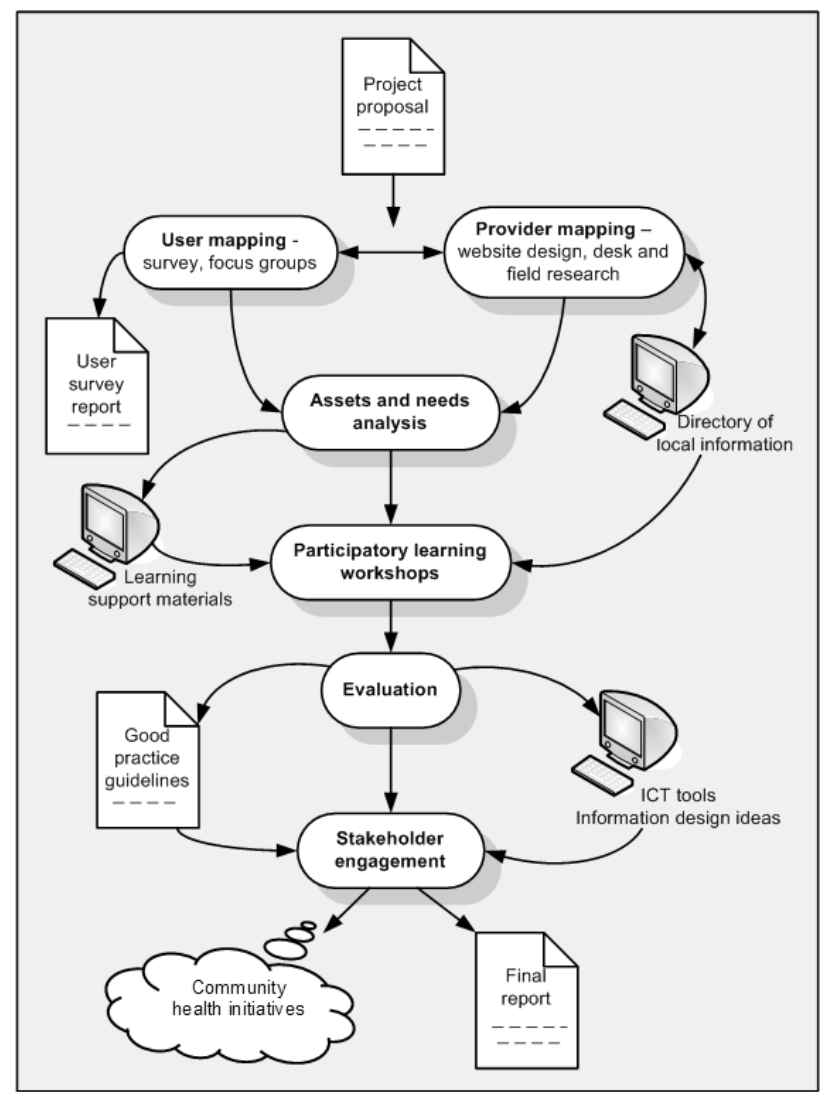

weight management, as well as their perceptions of weight and health and their use of ICTs. The target group for the survey was adult residents of Brighton and Hove who identified as being over the healthy weight for their height and trying to do something about it. The survey was written up as a report to the Department of Health and has been explored in Marshall et al. (2009). The results also fed in to the design of participatory learning workshops.

The workshops sat at the core of the Net.Weight study. Participants were given the opportunity to develop information and ICT skills to support their weight management activities and were also encouraged and supported to critique the information they found and the ICTs they used. The participants worked in the same groups over a period of 3 months. This approach was thus similar in some ways to the 'information review groups' used by Marshall and Williams (2006).

Workshop participants were recruited through 3 main routes: 
- The user survey, where respondents were given an opportunity at the end of the questionnaire to register their interest in workshops.

- Community engagement activities organised by the partner organisations and attended by members of the research team

- A community event organised by the research team at a local community centre. In this setting, early results from the survey were presented and workshop content ideas were generated with participants.

Before the workshops started, participants were asked to complete a short questionnaire to capture information about their health and weight, their uses of information and ICTs, and their expectations of the workshops. As well as helping to clarify the design of the workshops this data also provided a benchmark for comparison with the evaluative interviews held at a later stage. A total of 39 people attended at least one workshop, of whom 31 were female and 8 were male. The youngest participant was 19 and the oldest was 77, with an average age of 57. Only 1 person did not have access to the Internet at the start and most felt that they were either 'highly' or 'fairly' skilled at using computers and the Internet, although around a third of them reported themselves to be 'not very skilled'. Fewer than half of them used the Internet to search for information on weight.

A number of learning support materials were developed for the workshops. They included a website called Net.Weight.Community (Net.Weight 2008) which was used to provide access to learning materials, presentations and links to relevant information resources. It also became a means of capturing research data, in the form of posts made by participants.

The goal of the first workshop in each series, called Information Guided Tour, was to facilitate the exploration and evaluation of websites with content relevant to weight management. The first workshop also acted as a skills foundation for the later workshops, which explored social networking tools and, in the final workshop, a practical website design exercise. The format of the Information Guided Tour workshop was that two specific health-related sites were demonstrated on a projector screen, after which participants explored sites for themselves either using the links from the Net.Weight.Community site, or by putting their own search terms into Google or other search engines. Participants were encouraged to work in pairs, so that they could discuss what they were finding and they were asked to note down anything they found particularly interesting or relevant. This was followed by a group discussion. The two specific sites selected for demonstration were NHS Choices (NHS 2008) and Active for Life (Brighton and Hove City Council 2006), representing a national and a local provider respectively. At the time of the workshops $N H S$ Choices (NHS 2008) had been recently launched and was selected because of its rich content around weight management, multimedia content and opportunities for interactivity. Active for Life (Brighton and Hove City Council 2006) is provided jointly by Brighton and Hove City Council and the local NHS Primary Care Trust (PCT) and was selected because of its relevant content as an online directory of local healthy living activities and initiatives.

In the second half of the Information Guided Tour workshop, there was a demonstration of two Web-based evaluation tools, the Evaluating health information tutorial from the U.S. National Library of Medicine (NLM) (National Library of Medicine 2007) and an interactive tool called Quick (Health Education Authority and Centre for Health Information Quality 2000) [1]. The purpose of demonstrating assessment tools was to raise participant awareness of the existence and application of such tools. It also enabled the researchers to gain an insight into participants' opinions of the tools themselves. The reasons for selecting the two particular tools were that they were Web-based and therefore in a format easily incorporated into the workshop design, and they both addressed the subject of Internet-based health information, the focus of the workshops. The fact that the NLM tutorial was voice-based and offered an alternative to text was felt to be advantageous, as some of the participants had reported that they had limited literacy skills. It also highlighted the fact that the Internet offers information in a variety of media formats. Quick was originally designed for use with children in education settings and this was made clear to the participants. Its use of easy language combined with visual material again made it appropriate for those participants who had limited literacy skills, while its informal style matched the tone that the research team hoped to establish in the workshops. After the demonstration, the participants 
had a second opportunity to explore websites in pairs or on their own and to report back.

Data from the workshop activities and discussions was captured in the form of observation notes from the research team and comments recorded by participants themselves. This was done by means of post-it notes and, in the case of the quality evaluation exercise, a form which asked them to note the sites they had found useful and not useful; whether they trusted the information they found; and what made them trust that information or not.

The workshops took place throughout the summer in 2008 and, after an interval of 6 months, the research team conducted individual interviews with participants in order to evaluate the longer term impact of the workshops. Interviews were either faceto-face or by telephone, depending on the preference of the participant concerned and a semi-structured approach was used. Interviewees were asked in particular to reflect on their pre-workshop questionnaire responses and the extent to which their perceptions and activities had changed.

18 participants agreed to be interviewed. Of those, 14 were women and 4 were men. The youngest was 19 and the oldest 77, with 16 of the 18 interviewees in the 50+ age range. In their pre-workshop questionnaires, 4 interview participants had rated themselves highly skilled in using computers and the Internet; 6 fairly skilled and 6 not very skilled. 9 of those interviewed had used the Internet to find information on weight management before the workshops; 7 had not.

The workshop and interview data were entered into NVivo and coded for analysis.

\section{Information and interaction}

The range of information sources and support mechanisms available to people wishing to manage weight is considerable and the Net.Weight user mapping survey (Marshall et al. 2009) showed that people use a wide range of sources and a variety of media. This supports the findings from previous studies on self-care (Huntington et al. 2002; Ellins \& Coulter 2005). The sources which were most useful for Net.Weight survey respondents were slimming groups and food packaging. Also highly rated were friends and family, magazines, TV and health books. Thus it appears that for the Net.Weight respondents human and informal sources are as useful, if not more useful, than the more formal sources usually associated with health information. The studies by Ellins and Coulter (2005), Huntington at al. (2002) and the Department of Health (2005) all found that doctors or other healthcare practitioners were the most important or useful source of information. In contrast, the Net.Weight user mapping survey found that doctors were not a particularly useful source of information and, throughout the study, there were reports from participants about negative interactions with doctors which supported this finding. In contrast, the positive role played by slimming and other support groups was also a recurrent theme in the study and, for many participants, such groups provided a means for the informal exchange of information.

During the workshop phase of Net.Weight, the workshops themselves also became a setting for the informal exchange of information. This happened alongside the more formal or structured aspects of the workshop activities, particularly during the handson and discussion sessions, when participants increasingly shared information about a wide range of subjects including local restaurants, favourite recipes, leisure activities and advice along 'what worked for me' lines. Olivia [2], for example, discovered a website which gave details of a local radio show that broadcast an exercise class. As well as sharing the information with the others in her workshop group at the time, she posted about it on the Net.Weight. Community discussion forum:

It's really good - and fun - and includes a great buttock clenching few minutes where all listeners clench their buttocks for the duration of a song clench, relax, clench, relax, clench, relax ... Try it! [Olivia]

In her interview, Olivia again praised the radio programme and said that her reasons for alerting others to it was that she herself had found it useful, motivating and amusing.

Many other participants also spoke positively in their interviews about this information sharing aspect of the workshops, as illustrated in the following reflection:

I think collectively we had a lot of information and I think that was good. That was probably as 
big a part of it and as useful a part of it as any other. In that just people's own experiences which I suppose generally you find when you're with a group of people, that people's experiences are always really useful and interesting, aren't they? [Virginia]

The literature stresses user-information interaction. Williams (2008) is concerned with how this interaction can be made more effective, seeing the effective use of information as an empowering tool, not only for individuals but also for communities. However, the interaction between users and within communities and the way in which this interaction itself generates information is largely ignored in the literature. The consumer health information literature, for example, tends to draw a distinction between providers and users of information, largely ignoring the fact that people are often both. An exception to this is Childs (2004) who makes the point that in the context of sick children, support group workers are often themselves parents of such children and that both groups are equally knowledgeable about issues relating to their health conditions, with similar information needs and capabilities. The Net.Weight participants had a different profile from those involved in Childs' (2004) research, but both groups could be regarded as communities of practice (Wenger 1998), capable of generating as well as consuming information. This adds a further dimension to the idea of user-information interaction, that of useruser interaction, as a framework not only for using information but for providing it as well.

The Net.Weight participants also had in common with the participants in Childs' (2004) research the fact that they were knowledgeable about their condition: 'We all have the knowledge'. In answer to a question about the sources of information which help with weight management, the following answer is typical of the Net.Weight participants' responses: "... I think I know what I need to do - so maybe some source of support."

The implication of this type of observation is that information by itself is not enough. The Net.Weight study would suggest that information is closely linked in people's minds with other aspects of human interaction, such as support, advice and motivation. This would further explain the usefulness of slimming groups as a source of information. Childs $(2004,17)$ describes a staged information process, enabling people to receive information without being overwhelmed, for example with a new diagnosis. She suggests that "support groups are a vital part of this staging process, providing discussion and emotional support". The Net.Weight study suggests that some groups of people, such as those engaged in managing their weight over the long term, need ongoing support and that information and support are more closely inter-linked than has been generally acknowledged in the consumer health information literature.

These complexities challenge the traditional definitions of information, health and e-health literacy. The Institute of Medicine, for example, states that health literacy is "the degree to which individuals have the capacity to obtain, process and understand basic health information and services needed to make appropriate health decisions" (2004, 4, emphasis added). The other definitions are less explicit but nevertheless imply individual activity. Johnston and Webber argue that information literacy must be seen as a "socialized activity" $(2006,113)$. Their reconceptualisation of information literacy as a "soft applied discipline rather than ... a set of personal attributes" (Johnston \& Webber 2006, 109) echoes Nutbeam's (2008) argument about the need to see health literacy as an asset which enables engagement in social action. Findings from the Net.Weight study would appear to support an approach to information and health literacy which emphasises, or at least includes, a social as well as an individual perspective. Such an approach, incorporating useruser as well as user-information interaction, might help increase understanding of this interaction and its impact on people's information practices.

\section{Assessing quality}

As noted above, part of the aim of the Information Guided Tour workshop was to explore information quality assessment in the context of weight management. The participants had the opportunity to explore some of the online quality assessment tools for themselves and to apply the principles of assessment to the information they were finding online. Adams, Bont, and Berg (2006) found that a site or a tool worked when there was a 'fit' with established search processes. Many of the Net.Weight participants were new to searching and therefore did not necessarily 
have established search routines, but the study showed that people looked for a 'fit' with their own tacit knowledge or personal experience. One workshop participant commented of the tools that they are what an intelligent person would think anyway and another said that one's critical faculties "[...] come naturally." A third said: "It's more a matter of if a site feels right for you then you use it." In the post workshop interviews, participants re-iterated this theme: "You look at [a website] and think well this is a load of rubbish" [Olivia].

As anticipated by Marshall and Williams (2006), the concept of quality and how to assess it remained elusive for many Net.Weight participants: "Well, well I suppose it's really ... I mean if you look at a bad one that doesn't give you what you are looking for or set out badly, but I don't ... I can't sort of be quite specific" [Olga]. The way in which Olga is struggling to articulate her approach to assessing information exemplifies the difficulty that many Net.Weight participants experienced with regard to assessment.

The study supports the assertion from Adams, Bont, and Berg (2006) that people do not "have a standard list of points" when they assess information. As one interviewee said: "I'm not sure I actively look at things in that way" [Sasha]. Adams, Bont, and Berg $(2006,71)$ go on to suggest that instead of a list of points people "pragmatically juxtapose different signs in order to build their judgment" a contention which again is supported by some of the Net.Weight comments: "I can't judge it to the degree whether it's good information or bad information; I can only make a decision on if that information suits me" [Alexander]. Net.Weight thus adds weight to the argument articulated by Adams, Bont, and Berg (2006) that assessment tools add value only in as much as they align with already established processes.

It would be wrong, however, to suggest that the Net.Weight participants gained nothing at all from the quality assessment session. In the post-workshop interviews the participants were asked if they had noticed any difference in the way they assessed information as a result of the workshops. Several said that the workshops had made a positive difference to their evaluation skills, in that they were more questioning, and some reported unequivocal gains, particularly with regard to confidence: "I've learnt now which sites are better than the others, where it comes to help and advice ... and it's given me a lot more confidence to look up and not always take a word for anything and everything." [Sandy]

In complete contrast, Isabelle, who had serious health problems, had begun to question her information sources to the extent that she was unwilling to trust what she found,

"well, [the workshops] made me more wary, you know. Before maybe I would have just read something and thought 'oh that sounds good and just gone ahead', but now I sort of think, you know, 'well should I ...you know, do I know enough about it'?" [Isabelle]

She said that she now relied on her doctor and the specialists at the hospital, whom she trusted completely.

An unequivocal finding from the workshops and interviews was the importance of organisational authority as an indicator of trust. The BBC was cited a lot in this context, in part because of it being easily recognisable, a 'well-known name'. Of the NHS as a brand name, there was general agreement that ' $[. .$. anything with NHS on it or recommended by them' was trustworthy. The BBC elicited a similar response:

'The BBC is a bit like the NHS - you tend to trust it'

'We feel confident with the NHS ... It's the same with the BBC.'

As is hinted at in the above two quotes from workshop discussions, the idea of the BBC as an arm of government was articulated several times. In one workshop this made it trustworthy: "you can trust the BBC, it's more or less government run"; in another it made it untrustworthy, with one participant saying that she did not trust the BBC for news because of it being 'government-controlled'. Some felt that the government was acting in their interests and that it could be trusted because it 'doesn't have an axe to grind'. As Marshall and Williams (2006) point out, of course, governments do have 'axes to grind' and a few participants were critical of the government perspective. One workshop participant, Peter, argued that the government's agenda was to reduce levels of obesity because it would save the 
NHS money and that it was therefore in the business of propaganda: "it's in their interests to put the blurb out for what they need us to know."

Authority is therefore not a straightforward concept. Marshall and Williams (2006) point out that, according to assessment instruments such as DISCERN (Charnock et al. 1999), the authority of a source is not a reliable indicator of quality, since well-respected individuals or organisations can produce poor quality information. Indeed, there was an illustration of this in a Net.Weight workshop, when a participant said of the BBC Health site, 'it's the $\mathrm{BBC}$, it's got to be good', but once in the site she felt that there was too much information, it was boring and '... it took ages to find anything'. However, for most participants, authority was a key indicator of quality and Net.Weight reflects the findings from Marshall and Williams that "the organizational source of an information product appear[s] to be particularly important ..." $(2006,152)$.

Assessing health information quality was an integral part of Net.Weight but only one of many strands. The role of information quality assessment tools was important only in relation to the impact the tools had on participants' weight-related information activities. The picture that emerges, therefore, possibly reflects the complexity of real life situations more closely than the studies which have examined information assessment tools in isolation.

\section{The Web for weight management information}

In the Information Guided Tour workshop, the participants explored weight-related websites and reported back on those which they found most useful. The website mentioned most frequently as a useful source was $B B C$ Health, specifically the Healthy Living section (BBC n.d.). Individuals in all groups liked this site, commending it for its clear structure, navigation and language. In the post-workshop interviews, participants were still as enthusiastic: "I love that website for the BBC ... I just think it's so well laid out and so easy" [Natasha]. As Adams, Bont, and Berg (2006) reported, navigation is significant in the lay user's attribution of reliability and Childs (2004) reinforces this, stating that websites must be accessible and navigable. Childs goes on to argue, however, that good site design is "not the fi- nal arbiter for acceptance of information" and advocates the inclusion of "interaction and feedback" $(2004,17)$ into sites. In terms of interaction it might have been expected that the NHS Choices site, which was demonstrated in this workshop, would have struck a chord with participants. However, this was not the case and the participants did not find the site engaging, preferring the straightforward information provision model of $B B C$ Health (BBC n.d.). This could be attributed to familiarity with the $\mathrm{BBC}$ and the authority issue discussed above or it could relate to the willingness of this particular age-group to accept a traditional information provision model. More research on user interaction with NHS Choices is required before more definite conclusions can be drawn.

The key factor which made participants dislike or mistrust a site was commercialism. Sites which required payment for information or services or which carried advertisements were felt by most to be inherently untrustworthy: "I do avoid the ones that ask me for money up front before I do anything" [Sasha]. In this, there was a more of consensus in Net.Weight than reported by Marshall and Williams (2006), possibly also again reflecting the Net.Weight agegroup.

\section{The need for specific information}

As suggested by Adams, Bont, and Berg (2006), patients are not interested in "scores of general information" and that what they expect are "individual pages containing tailor-made answers to their specific questions". In Net.Weight, as noted above, people were already knowledgeable about weightrelated issues. However, many expressed a need for information which was specific to their personal situation, often related to other health problems. One survey respondent wanted information about exercise for osteoarthritis and another wanted advice on foods that might help lower blood pressure. Laila, a disabled woman confined to a wheelchair, said at the first workshop that she would like to find recipes that were simple so that she could make them sitting down. Not everyone's needs were quite so specific, in the way suggested by Adams, Bont, and Berg (2006), but the 'specific' theme was expressed in other ways. One workshop participant pointed out the flawed logic on websites with a single 
section for the 50+ age group, "If you're over 70, you don't want aerobics!" When participants did find information on the Web that related to their personal needs, there was a sense of triumph. Natasha, who was diagnosed with high cholesterol shortly before the workshops began, told her workshop group that she had found a website with specific advice on relevant diets, including a free diet sheet. She had found this on her own, after the first workshop, using newly discovered searching skills.

A further way in which the theme of specific information was expressed was in the need for information that related to the local area. As in the example of the 'fat club' radio broadcast cited above, participants sought out and valued information with a local focus. However, the local Active for Life website generated conflicting opinion at the first workshop. Some participants found it useful for information about local dance classes, swimming sessions and guided walks. One participant said that she would never have thought of looking on the Web for this information "... but it's all there." However, many found it boring and did not grasp the fact that it was essentially a directory of local activity, reinforcing the importance of visual appeal and appropriateness for assessing reliability (Marshall \& Williams 2006).

The concept of local had a further dimension, that of involvement at local level. Participation in Net.Weight had given several people the confidence and desire to be involved in other local initiatives. Two of the participants reported how they had been encouraged by participating in Net.Weight to volunteer for a local project initiated by the NHS Brighton and Hove City Teaching Primary Care Trust. Others spoke about the need for information providers to adopt more participative approaches around information and health:

"I do wish the local authority would push out some more stuff just generally. You know if you look on their website there's really nothing there ... I mean I wonder why they don't just invite people along to sort of discuss how as a local authority they could make the residents healthier." [Virginia]

The Net.Weight study would thus support Childs' (2004) idea of a 'local web of trust' which would bring together voluntary and statutory organisations in health information provision. Net.Weight would suggest further that there is also a role for people who are not necessarily part of an organisation but who form a "community of practice" (Wenger 1998), willing to work together over a shared interest or issue.

\section{Where the Internet 'fits'}

At the interview stage of the study, participants were asked to reflect on whether their information sources had changed as a result of participating in the study, particularly on their use of the Internet as a gateway to information. The analysis demonstrated that making people aware of the Internet made a real difference to some, particularly those who had not used it previously. Some talked enthusiastically about how the Internet was now a part of their daily routine and how they enjoyed receiving email alerts from weight management organisations or checking websites such as the BBC for updates. In the case of one participant, the discovery of Internet resources had made a considerable impact on his life:

"I went mad with the internet and the laptop for those first couple of workshops, trying to explore and extract all that information ... it has sort of, it's given me another dimension to my life really." [Alexander]

However for many of the participants, the workshops made little difference to their information sources and they were no more disposed to use it after than before the workshops. Several said that they had found the workshops useful and interesting but that they were not really interested in using the Internet, for information or for social networking, on an ongoing basis. One woman, Olga, talked about her use of the Internet for other aspects of her life such as for travel information or help with crosswords but how, for weight management, "it didn't inspire me to go that way."

These findings again demonstrate the importance of 'fit'. If new practices added value and could be integrated into their daily lives, the participants embraced them; if they did not appear to add value and did not 'fit' with their daily routines, they were rejected. This takes the concept of 'fit' further than Adams, Bont, and Berg (2006) who apply it specifi- 
cally to the "already established search processes of patients". Net.Weight suggests that it applies also to those people who are not "patients", but are concerned with health issues, in this case weight management. It also suggests that it applies not only to those involved in the types of active information seeking implied by "established search processes" but also to those involved in other modes of information practice, such as those described by McKenzie (2003) in her continuum model.

\section{Conclusion}

The Net.Weight study took an "innovative approach to interaction between people and information" (Kuhlthau 2008, 71). Through the use of participatory learning workshops, it demonstrated that the interaction between people is an important aspect of the information process, which is often neglected in the literature. It suggests that exploring the user-user dimension might add to the understanding of information effectiveness. It also suggests that an approach to information and health literacy which includes a social as well as an individual perspective is necessary. On quality assessment, Net.Weight supports the findings from other studies such as that by Marshall and Williams (2006) that organisational authority is a key measure of reliability for lay users, and that quality assessment tools have a limited role in helping certain groups of health information consumers appraise information. The Net.Weight participants preferred the traditional information provision model of $B B C$ Health (BBC n.d.) to the more innovative approach adopted by NHS Choices (NHS 2008), but more research is required to ascertain the reasons for this. The need for information which is tailored to specific need and which has local relevance was widely expressed. The potential of websites such as NHS Choices (NHS 2008) to do this was recognised, but the idea of some sort of method for supporting for local participation, similar to Childs' (2004) "local web of trust" was attractive to many. The Net.Weight participants embraced the Internet as a medium for weight management information only when it added value to their existing information and weight management practices, and when it could be integrated into their everyday lives.

\section{Notes}

1. The Quick website is no longer available

2. All participants' names have been changed in this paper

\section{References}

Adams, S., A. de Bont, and M. Berg. 2006. Looking for answers, constructing reliability: an exploration into how Dutch patients check Web-based medical information. International Journal of Medical Informatics 75 (1): 66-72.

BBC. n.d. BBC health / Healthy living. URL: http://www.bbc. co.uk/health/healthy_living/ [viewed 22 June 2009].

Brighton and Hove City Council. 2006. Active for Life: More People, More Active, More Often URL: www.activeforlife. org.uk [viewed 22 June 2009]

Charnock, D., S. Shepperd, G. Needham, and R Gann. 1999. DISCERN: an instrument for judging the quality of written consumer health information on treatment choices. Journal of Epidemiological Community Health 53: 105-11.

Chartered Institute of Library and Information Professionals. 2007. Information literacy: definition. URL: http://www. cilip.org.uk/policyadvocacy/learning/informationliteracy/ definition/definition.htm. [viewed 12 October 2009]

Childs, S. 2004. Developing health website quality assessment guidelines for the voluntary sector: outcomes from the Judge Project. Health Information and Libraries Journal 21 (Suppl 2): 14-26.

Cline, RJW., and KM. Haynes. 2001. Consumer health information seeking on the Internet: the state of the art. Health Education Research 16 (6): 671-92.

Coulter, A., and J. Ellins. 2006. Patient-focused interventions: a review of the evidence. London: The Health Foundation.

Department of Health. 1998. Information for health: an information strategy for the modern NHS, 1998 - 2005. London: Department of Health.

Department of Health. 2001. Building the information core implementing the NHS Plan. London: Department of Health.

Department of Health. 2004. Better information, better choice, better health, London: Department of Health.

Department of Health. 2005. Public attitudes to self care: baseline survey. London: Department of Health.

Ellins, J., and A. Coulter. 2005. How engaged are people in their health care? London: The Health Foundation.

Eysenbach, G., and C. Kohler. 2002. How do consumers search for and appraise health information on the World Wide Web?: Qualitative study using focus groups, usability, tests and in-depth interviews. British Medical Journal 324: 57377.

Eysenbach, G., J. Powell, O. Kuss, and E. Sa. 2002. Empirical studies assessing the quality of health information for consumers on the World Wide Web - a systematic review. Journal of the American Medical Association 287(20): 2691-700.

Health Education Authority and Centre for Health Information Quality. 2000. Quick: the quality information checklist. URL: http://www.quick.org.uk [viewed 9 January 2009] 
Henwood, F., A Marshall, L Carlin, ES. Guy, and H. Smith. 2009. Net.Weight Project: executive summary. URL: http:// research.cmis.brighton.ac.uk/netweight/system/files/Executive +summary+december+2009_0.pdf [viewed 3 March 2010]

Huntington, P., D. Nicholas, P. Williams, and B. Gunter. 2002. Characterising the health information consumer: an examination of digital television users. Libri 52(1): 16-27.

Institute of Medicine. 2004. Health literacy: a prescription to end confusion. Washington, DC: National Academies Press.

Johnston, B., and S Webber. 2006. As we may think: information literacy as a discipline for the information age. Research Strategies 20(3): 108-21.

Kars, M., LM. Baker, and FM. Wilson. 2008. The Medical Library Association guide to health literacy. New York: NealSchuman.

Kuhlthau, C., 2008. From information to meaning: confronting challenges of the twenty-first century. Libri 58(2): 66-73.

Marshall, L.A. and D. Williams. 2006. Health information: does quality count for the consumer?: how consumers evaluate the quality of health information across a wide variety of media. Journal of Librarianship and Information Science 38(3): 141-56.

Marshall, A., F. Henwood, L. Carlin, ES. Guy, T. Sinozic, and H Smith. 2009. Information to fight the flab: findings from the Net.Weight study. Journal of Information Literacy 3(2.) URL: http://ojs.lboro.ac.uk/ojs/index.php/JIL/article/view/ PRA-V3-I2-2009-3 [viewed 3 march 2010]

McKenzie, PJ. 2003. A model of information practices in accounts of everyday-life information seeking. Journal of Documentation 59(1): 19-40.

Medical Library Association. 2005. Communicating health information literacy. URL: http://www.mlanet.org/pdf/ healthlit/hil_comm_plan.pdf [viewed 10 October 2009].
National Health Service. 1999. NHS Direct Online URL: http:// www.nhsdirect.nhs.uk [viewed 12 October 2009]

National Health Service. 2008. NHS Choices URL: http:// www.nhs.uk [viewed 12 October 2009]

National Health Service. 2009. Information prescriptions URL: http://www.informationprescription.info [viewed 12 October 2009]

National Library of Medicine. 2007. Evaluating Internet health information: a tutorial from the National Library of Medicine URL: http://www.nlm.nih.gov/medlineplus/webeval/ webeval.html [viewed 12 October 2009]

Net.Weight. 2008. Net.Weight.Community URL: http://research. cmis.brighton.ac.uk/netweight.community [viewed 12 October 2009]

Norman, CD., and HA. Skinner. 2006. eHealth literacy: essential skills for consumer health in a networked world. Journal of Medical Internet Research 8(2): e9.

Nutbeam, D. 2008. The evolving concept of health literacy. Social Science and Medicine 67: 2072-2078.

Wenger, E. 1998. Communities of practice: learning, meaning and identity. Cambridge: Cambridge University Press.

Williams, D. 2008. Information: interactions and impact $\left(\mathrm{i}^{3}\right)-$ an introduction. Libri 58(2): 63-65.

Wilson, P. 2002. How to find the good and avoid the bad or ugly: a short guide to tools for rating quality of health information on the Internet. British Medical Journal 324: 598602.

World Health Organization. 1998. Health promotion glossary. Geneva: World Health Organization.

Paper received: 20 October 2009; revised version received: 3 March 2010; accepted 8 March 2010 